\title{
Communities of Practice for Teaching and Learning Mathematics
}

\author{
Michael Gr. Voskoglou* \\ Department of Mathematical Sciences, Graduate Technological Educational Institute of Western Greece \\ *Corresponding author: mvoskoglou@gmail.com
}

Received April 14, 2019; Revised May 19, 2019; Accepted June 12, 2019

\begin{abstract}
The target of the present study is to illustrate the importance of the communities of practice for teaching and learning mathematics. This is a composite subject that requires the discussion and analysis of several factors including a general introduction to the communities of practice, the status of mathematics education in the modern society, the desired learning skills of the $21^{\text {st }}$ century, the profile of the competent teacher of mathematics, the sociocultural views for the teaching and learning of mathematics, etc. All the above factors are combined here to present ideas and conclusions about the form, the role, and the usefulness of the communities of practice for teaching and learning mathematics, especially for the developing countries. Although this is not a new idea, it is believed that the analysis of the subject provided here is interesting and useful for the reader.
\end{abstract}

Keywords: Communities of Practice (CoP's), virtual CoP's, learning skills, competent teacher of mathematics, socio-cultural theories for the teaching and learning mathematics

Cite This Article: Michael Gr. Voskoglou, "Communities of Practice for Teaching and Learning Mathematics." American Journal of Educational Research, vol. 7, no. 6 (2019): 386-391. doi: 10.12691/education-7-6-2.

\section{Introduction}

The new technologies and especially the development of computers have made easy the communication among people from different countries and continents. As a result, the Communities of Practice (CoP's) appear today as having the potential of facilitating the cooperation among those people and in particular among developed and developing countries.

Education is a field offering many possibilities for such kind of cooperation. Experiences can be shared, ideas can be exchanged, educational problems can be solved, new methods or means of teaching/learning can de transferred, etc.

The target of the paper at hand is to discuss such kind of possibilities for the teaching and learning of mathematics. This is done as follows: Section 2 is devoted to a brief and general introduction to CoP's. In Section 3 the status of Mathematics Education in the modern society is examined, while Section 4 is focused on the characteristics of the competent teacher of mathematics. The required learning skills of the $21^{\text {st }}$ century are presented in Section 5, while Section 6 reviews the socio-cultural theories for teaching and learning mathematics. All the above topics are combined in Section 7 to present ideas about the form, the role, and the usefulness of the CoP's for the teaching and learning of mathematics and the article closes with the general conclusion stated in Section 8.

\section{Communities of Practice}

The Communities of Practice (CoP's) are groups of people (experts or practitioners in a particular field) who share a concern for something they do and learn how to do it better as they interact regularly, having therefore the opportunity to develop themselves personally and professionally. The group can evolve naturally because of the members' common interest in a particular domain, or it can be created specifically with the goal of gaining knowledge related to their field. For example, a group of engineers working on similar problems, a network of surgeons exploring novel techniques, a gathering of first-time managers helping each other, etc., are some characteristic cases of CoP's

CoPs are not new phenomena; this type of learning practice has existed for as long as people have been learning and sharing their experiences through storytelling. The cognitive anthropologists Jean Lave and Etienne Wenger coined the term CoP's in their 1991 book "Situated learning" [1], and Wenger then significantly expanded on the concept in his 1998 book, "Communities of Practice" [2].

Since then CoP's have been in the focus of attention, first as a theory of learning and later as part of the field of knowledge management and of many other human activities. Among the many studies and researches about CoP's that are available in the literature, Hildreth \& 
Kimble [3] offer a review on how the concept has changed over the years. Lesser and Stock ([4], p.836) identify four areas of organizational performance that can be affected by CoP's :

- Decreasing the learning curve of new employees

- Responding more rapidly to customer needs and inquiries

- Reducing rework and preventing "reinvention of the wheel"

- Spawning new ideas for products and services

CoP's are also known under various other names, such as learning networks, thematic groups, tech clubs, etc. Not everything called a community is a CoP. A neighbourhood for example, is often called a community, but it is usually not a CoP. It is the combination of the following three characteristics that constitutes a $\mathrm{CoP}[2]$ :

- The domain: It provides the general area of interest for the $\mathrm{CoP}$ that distinguishes its members from other people.

- The community: The members of a CoP engage in joint activities and discussions, help each other, and share information. But the members of a $\mathrm{CoP}$ do not necessarily work together; they could communicate in special meetings, or through the web (virtual CoP's), etc.

- The practice: The members of a CoP develop a shared repertoire of experiences, tools, ways of addressing recurring problems, etc., in short of a shared practice.

Close to the CoP's are the communities of interest. The main difference in this case is that their members are not necessarily experts or practitioners around the domain of the community; one needs only to be interested on the subject. On the contrary, a project team, although it meets to share and exchange information and experiences just as a $\mathrm{CoP}$, it differs from a CoP in several ways. For example, its members remain consistent in their roles during the project and the team is dissolved once its mission is accomplished.

\section{The Mathematics Education in the Modern Society}

Mathematical activity is an original and natural element of human cognition. According to Wittman ([5], pp. 359-360), in our modern society mathematics must be conceived as a broad social phenomenon whose diversity of uses and modes of expression is only in part reflected by specialized mathematics, as typically found in university departments of mathematics. This diversity includes mathematics developed and used in science, engineering, economics, computer science, statistics, industry, commerce, art, daily life, and so forth, according to the customs and requirements specific to these contents.

Mathematics educators and teachers need to have a lively interaction with mathematics and they must devote an essential part of their professional life to stimulating, observing and analyzing genius mathematical activities of children and students.

As part of mathematics, specialized mathematics must be taken into consideration as one point of view that, however, has to be balanced with other points of view.
The history of mathematical education clearly demonstrates the risks of following specialized mathematics too closely; perhaps the best example of this mistake being the failure of the introduction of the "new mathematics" in school education. A second mistake is that educationally important fields of mathematics, which are no longer alive in specialized research and teaching, have lost the proper attention in our schools today. A characteristic example is the Euclidean geometry with its great pedagogical value (e.g. see [6], Section 4). Imagine, for instance, the difficult position of a university teacher of mathematics in a department of Architecture or of Civil Engineering, who wants to present, some topics from the theory of surfaces - that constitutes the necessary mathematical background for the design of the roofs of the buildings - when students have difficulty even to realise that a straight line in space can be defined as the section of two levels!

Mathematics educators and teachers must see the school mathematics as an extension of pre - mathematical human capabilities, which are developed within the broader societal context provided by mathematics [7]. It is only from this perspective that the unity of mathematics teaching, from the primary through the upper secondary level, can be established. It would also be beneficial, if the mathematics specialists perceive themselves as partners in the larger mathematical system described above. Without some change of awareness on their part, any attempt to change the public image for mathematics is very difficult to succeed.

The teachers must take part in the design of the teaching units, but this can be no excuse for mathematics educators to retrain from this task. On the contrary, the design of substantial teaching units and of curricula is a difficult task that must be carried out by the experts in the field. By no means can it be left to the teachers, though teachers can certainly make important contributions within the framework of design provided by experts, when they are members of or in close connection with a research team. However, the adaptation of the teaching units to the conditions of a special classroom requires design of a minor scale, which must be carried out by the teachers. In other words, a teacher can be compared more to a conductor than to a composer, or perhaps better to a director than to a writer of a play, with the second roles corresponding to the researcher of mathematics education.

In concluding, mathematical educators and teachers of mathematics, regardless of personal beliefs and options, ought to prepare the conditions under which the mathematics education will receive and assimilate gently and creatively the advancing changes in the science of mathematics, getting the maximum possible profit from them.

\section{Learning Skills of the $21^{\text {st }}$ Century}

The specialists on the subject agree that the most important learning skills for the 21 st century are critical thinking, creative thinking, communicating, and collaborating [8]. These skills, often called the " 4 C's", help students to learn, and so they are vital to success in school and beyond.

When people speak of "left brain" activity, they are usually referring to critical thinking, which is connected to 
a careful study of something to better understand it. Some of the main characteristics of critical thinking involve analysis and synthesis, arguing, classifying, comparing and contrasting, defining, describing, evaluating, explaining, problem solving, etc.

Creative thinking is an expansive, open-ended invention and discovery of possibilities. When people speak of "right brain" activity, they most often mean creative thinking. Some of the more common creative thinking abilities involve brainstorming ideas, combination of materials according to a plan or perhaps based on the impulse of the moment, designing something for a specific purpose, making conversation, entertaining other people, innovating, flipping something to get a new perspective, questioning actively into what is unknown to make it known, etc.

Communicating is focused on deciding the most appropriate way to deliver a message ranging from a faceto-face chat to a written report. It involves the abilities of speaking, reading, and writing properly, of evaluating messages, of listening actively, of asking questions, and of otherwise engaging in the ideas being communicated. It also requires understanding the abilities and limitations of any technological communication, from phone calls to instant messages and e-mails.

Collaborating means to cooperatively working in a team for achieving a common goal. It requires decision-making first for sorting through the many options provided to the group and arriving at a single option to move forward. It also involves assigning duties to the members of the group and evaluating products and processes to provide a clear sense of what is working well and what improvements could be made. Leading a group means creating an environment in which all members can contribute according to their abilities, managing time, tracking the progress toward goals and resolving the occurring conflicts.

Computational thinking is another learning skill of the $21^{\text {st }}$ century of great importance. The term was brought to the forefront of the scientific society by Wing [9], who described it as "solving problems, designing systems and understanding human behaviour by drawing on concepts fundamental to computer science". According to Liu and Wang [10], computational thinking is a hybrid of other modes of thinking including abstract, logical, modelling, and constructive thinking. Computational thinking does not propose that problems need to be solved in the same way that a computer tackles them, but it actually synthesises critical thinking and existing knowledge and applies them for solving complex real life and technological problems [11]. Learning to think computationally or to problemsolve through abstraction is the ability to eliminate details from a given situation in order to find a solution that might not be forthcoming under other circumstances.

All of today's students will go on to live a life heavily influenced by computing, and many will work in fields that involve or are influenced by computing. There is therefore a need to start teaching computational thinking early and often [12]. Computer science is not just about programming, it's about an entire way of thinking, which is now an intrinsic part of our lives. Recent studies in this field address the necessity to become trained in thinking computationally before learning programming [13].

\section{The Profile of the Competent Teacher of Mathematics}

The common experience teaches that a brilliant mathematician need not be a good teacher of mathematics. However the converse of this argument is not true, because a good teacher of mathematics must be first of all a good mathematician. In fact, in order to be able to help efficiently students to understand mathematics and to use it properly in their everyday lives, the teachers must be able first to do so for their selves. Further, a wide and deep knowledge of the mathematical topics relevant to the teaching subject enables the teacher to acquire a spherical view on it, which helps to have a good teaching performance.

It is well established that students who do not acquire the correct mathematical background in primary school, it is difficult to perform well in mathematics later. However, in many countries the teachers of primary education are usually teaching mathematics together with language, history, physical sciences, etc., i.e. they are not specialized in mathematics. As a result many of them have not the proper mathematical background needed for teaching mathematics.

On the contrary, the teachers of mathematics of the secondary education are usually graduates of a mathematics department of a university. However, many of them follow other directions instead of mathematical education (pure or applied mathematics, statistics, etc.), and they finally decide to become high school teachers because they cannot find another job. Consequently, they have not the proper pedagogical background needed for their job. It is true of course that many mathematicians became good teachers despite to the fact that they had never attended courses on the didactics of mathematics and (or) on pedagogical studies.

The question therefore is: To be a competent teacher of mathematics is actually a talent, or it is something that must be acquired through the proper professional training? I think that the truth lies somewhere in the middle. To be a good teacher is indeed a talent, but this talent must be cultivated through the proper training. In fact, under the pressing demands of the modern society, the teaching experience is not enough to mark out this talent, as it happened in the older times of a much simpler and less demanding society. On the contrary, I believe that less talented students could become nowadays competent mathematics teachers through the proper professional training.

But which must be the proper training for someone to become a competent mathematics teacher? Is a competent teacher someone who has been trained in mathematics and receives some additional pedagogical or didactical training of theoretical and of practical nature, or someone who has received pedagogical training and moves on to teaching mathematics after having had some amount of mathematical training? Should the mathematics teachers learn mathematics as such without particular regard to their future teaching profession, or should they learn mathematics in ways that are specifically focused on teaching at certain levels, i.e. focused on what Schulman [14] calls "pedagogical content knowledge"?

Yet another issue is the balance between theoretical study in a teacher training institution and practical work in 
school. Delicate balances have to be struck and genuine dilemmas have to be resolved for the design, structuring and organization of pre - service education and in service professional development of mathematics teachers. But are the mathematics teacher training institutions today in position to offer the proper training to their students and future teachers? The answer to this question seems to be rather unsteady and complicated. In fact, as professional schools are more and more absorbed into the general culture of the university, they hanker after academic respectability. In terms of the prevailing norms, academic respectability calls for subject matter that is intellectually tough, analytic and formalized [15]. Thus quite a number of mathematical educators and researchers of mathematics education instead of working into the core of mathematical education, are taking the approach to adopt methods and standards from the hard sciences and humanities, where the scientific background and their natural interests might be as influential as the wish to be recognized and supported by scientists in the related disciplines. Consequently, a great deal of didactic research adheres to mathematics, history and philosophy of mathematics, psychology, pedagogy, sociology and so forth. Thus the holistic origin of didactic thinking, namely mathematical activity in social contexts, is neglected. Very often also the adoption of frameworks and standards from related disciplines is linked to the dogmatic claim that those frameworks and standards are the only ones possible for didactics. In the views of many researchers this is a big problem that presently inhibits major progress in mathematics education.

Niss [16] suggests a new way to educate competent mathematics teachers, which has been developed as part of a larger project in Denmark, the so - called KOM project. According to the results of this project a competent mathematics teacher is one who in an efficient and effective way is able to help students to build and develop the following eight mathematical competences, which are divided in two groups:

1. Mathematical thinking (mastering mathematical modes of thought), problem handling (formulating and solving mathematical problems), modelling (being able to analyze and build mathematical models concerning other subjects or practice areas) and reasoning (being able to reason mathematically).

2. Representation (being able to handle different representations of mathematical entities), symbol and formalism (being able to handle symbol language and formal mathematical systems), communication (being able to communicate in, with, and about mathematics) and aids and tools (being able to make use of and relate to the aids and tools of mathematics).

The competencies of the first group characterize the ability to ask and answer questions in and with mathematics, while those of the second group characterize the ability to deal with the mathematical language and tools.

Also a competent mathematics teacher must posses the following six didactical and pedagogical competencies:

- Curriculum competency (to analyze, assess and implement existing mathematics curricula and to construct new ones).
- Teaching competency (to plan, organize and carry out mathematics teaching, including creation of a rich spectrum of teaching/learning situations).

- Uncovering of learning competency (to answer, interpret and analyze students' learning of mathematics, as well as their beliefs and attitudes towards mathematics).

- Assessment competency (to assess, characterize and communicate student learning outcomes and to inform and assist the individual student and other relevant parties).

- Collaboration competency (to collaborate with different sorts of colleagues in and outside mathematics, as well as others - parents, authoritiesconcerning mathematics teaching and its conditions), and

- Professional development competency (to participate in activities of professional development, such us in-service courses, projects, conferences, and to keep oneself up-dated about new developments and trends in research and practice).

In concluding, Niss [16] admits that the adoption from a country of the above way of looking at mathematics teachers' competencies and their development during pre-service education and in-service professional development training most probably poses substantial challenges to its educational system.

All the above were thoroughly discussed in a workshop on the role of the teacher for the learning of mathematics that I had organized within the $59^{\text {th }}$ CIEAEM Congress [17]. The participants of the workshop (teachers, mathematical educators and researchers from all over the world) underlined the fact that the pre-service education and the in-service training of the teacher, even if they are of good quality, they are not enough to create the competent mathematics teacher. For this, a continuous personal effort of the teacher is also needed for his (her) improvement with the help of the experience that he (she) gradually gets from practicing with the teaching of mathematics and with a continuous self-training on the recent developments of mathematics and of mathematics education.

\section{Socio-Cultural Views for the Teaching and Learning of Mathematics}

The constructivist view of learning and the sociocultural theories have been recently highly influential in addressing mathematical knowledge and the learning of mathematics.

The constructivist view involves two principles: First that knowledge is actively constructed by the learner, not passively received from the environment, and second the importance of the "coming to know", which is a process of adaptation based on and constantly modified by the learner's experience of the world [18].

On the other hand, according to the socio-cultural approach, which is based on constructivism, learning takes place within some socio-cultural setting. Shared meanings are formed through negotiation in the learning environment, leading to the development of common knowledge. 
Mathematics teaching is intended to promote the learning of mathematics. But, while theory provides us with lenses for analyzing learning, the position of mathematics teaching remains theoretically anomalous and underdeveloped [19]. We might see one of the problems to lie in the relationships between learning, teaching and the practice of teaching. Theories help us to analyze, or explain, but they do not provide recipes for action; rarely do they provide direct guidance for practice.

According to Jaworski [19] one way to draw on theories of learning to explain or characterize teaching is to see teaching as a social practice, in which teachers are practitioners. For example, like the novice tailor being drawing in to the practice of tailoring by practicing alongside perfecting processes and skills, by learning the trade etc., we might see the novice teacher being drawn similarly into the practice of teaching.

Jaworski [19] suggests for the practice of teaching a form of critical alignment, in which it is possible for participants to align with aspects of practice while critically questioning roles and purposes as a part of their participation for on going regeneration of the practice.

Several authors and researchers, supporters of the socio-cultural approach, focus on the importance of the inquiry communities and their contribution to learning and development of teaching [19,20,21]. Inquiry here is understood to be the process to know through creative exploration. In this sense inquiry is closely related to the concept of research, demanding however less formality than the latter. Jaworski [19] addresses the following three forms of inquiry practice:

- Inquiry in learning mathematics (for students and teachers): Students in schools are learning mathematics through exploration in tasks and problems in classrooms. Teachers are using inquiry as a tool to promote students learning in mathematics.

- Inquiry in teaching mathematics (for teachers and educators): Teachers are using inquiry to explore the design and implementation of tasks, problems and activity in classrooms. Educators are using inquiry as a tool to enable teachers to develop teaching.

- Inquiry in research for developing the teaching of mathematics: Teachers, educators and researchers of mathematics education are investigating the processes of using inquiry in learning and teaching of mathematics.

In concluding, the socio-cultural approach supports the collaborative teaching and learning of mathematics with the help of the constructivism.

\section{CoP's in Mathematics Education}

All those discussed in the previous sections of the present study illustrate the fact that the support of mathematics teachers to meet the complex and demanding visions of their job is a difficult task. But, even if the pre-service education and the in-service training of the teacher are of good quality, a continuous personal effort for self-training and improvement is also needed to create a competent mathematics teacher. On the other hand, since most human activities involve some form of teaching and learning, it is crucial to understand that the learning of mathematics cannot be based only on formal school contexts, but it must be also connected to the everyday life.

The socio-cultural views facilitate both the connection of mathematics to the everyday life and the development of teaching. The inquiry communities among students and teachers, and among teachers, educators and researchers of mathematics education, which are actually a form of CoP's, constitute an important component of the socio-cultural approach for teaching and learning mathematics at all levels of education, from elementary to tertiary.

A comprehensive review of the development of CoP's for teaching and learning in general can be found in the book [22]. CoP's can play in particular an important role in modifications to teaching and learning mathematics for the needs of the $21^{\text {st }}$ Century, by facilitating the communication and collaboration among students, teachers and researchers and by addressing the challenge of inquiry based learning of mathematics that advances critical thinking. Within a structured curriculum educational setting this could be succeeded both in and outside of the classrooms as a supplement of the formal school activities. Several studies are available in the literature on CoP's for teaching and learning mathematics (e.g. $[23,24]$, etc.).

As we have seen in our introduction, the development of the new technologies have enhanced the benefits from the function of CoP's for their members by making easier the long distance communication among people. The computers in particular play nowadays an important role in mathematics education. In fact, the animation of figures and of mathematical representations, provided by suitable computer software packages, increases the students' imagination and helps them in finding easier the solutions of the corresponding problems. The role of mathematical theory after this is not to convince, but to explain.

For all the above reasons the virtual CoP's through the web appear today as a very promising tool for a further development of the teaching and learning of mathematics, especially for the developing countries. Our proposition, adopting the Jaworski's model of the inquiry communities, involves two types of virtual CoP's:

1. Students and teachers from developed and developing countries for learning mathematics and

2. Teachers, educators and researchers of mathematics education from developed and developing countries for teaching mathematics and for research on the teaching of mathematics.

The benefits of such kind of collaboration are almost obvious. In fact, the scientists of the developing countries have usually low budgets for travelling abroad to participate in international conferences and other scientific or professional meetings. For similar reasons, the opportunities of their students to participate in educational exchanges are limited. Therefore the virtual CoP's facilitate the contacts among scientists and students of the developed and the developing countries for exchanging ideas, experiences, teaching and learning methods and techniques, software for teaching and learning mathematics, scientific information, etc. 


\section{Conclusion}

Teaching and learning to teach are social practices and collaborative enterprises. That is why research in teacher education has become increasingly concerned with teachers' development from perspectives rooted in socio-cultural views of learning. Learning is an integral part of our everyday lives. It is part of our participation in our communities and organizations. The problem is not that we do not know this, but rather that we do not have very systematic ways of talking about this familiar experience. Wenger's social theory of learning and the notion of CoP's are becoming popular nowadays as a conceptual framework for exploring the learning processes and the teaching of mathematics. An analysis of the reasons of this phenomenon was attempted in the present study, which is believed to be interesting and useful for the reader.

\section{References}

[1] Lave, J., Wenger, E., Situated Learning: Legitimate Peripheral Participation, Cambridge: Cambridge University Press, 1991.

[2] Wenger, E., Communities of Practice: Learning, Meaning, and Identity, Cambridge: Cambridge University Press, 1998,

[3] Hildreth, P., Kimble, C., Knowledge Networks: Innovation through Communities of Practice, London / Hershey: Idea Group Inc., 2004.

[4] Lesser, L.E., Storck, J. "Communities of Practice and organizational performance", IBM Systems Journal, 40(4), 2001.

[5] Wittman, E., "Mathematics Education as a Design Science", Educational Studies in Mathematics, 29(4), 356-374, 1995.

[6] Voskoglou, M. Gr., "Formalism and intuition in mathematics: The role of the problem", Quaderni di Ricerca in Didactica (Univ. of Palermo), 17, 113-120, 2007.

[7] Dörfler, W. (1994), "The gulf between mathematics and mathematics education", ICMI study, What is research in mathematics education and what are its results? Washington, May 8-11, 1994.

[8] Thoughtful learning.com, "What are learning skills?", retrieved from https://k12.thoughtfullearning.com/FAQ/what-are learningskills, 2019.

[9] Wing, J. M., "Computational thinking”, Communications of the $A C M, 49,33-35,2006$
[10] Liu, J. \& Wang, L., "Computational Thinking in Discrete Mathematics", IEEE $2^{\text {nd }}$ International Workshop on Education Technology and Computer Science, 413-416, 2010.

[11] Voskoglou, M. Gr. \& Buckley, S., Problem Solving and Computers in a Learning Environment, Egyptian Computer Science Journal, 36 (4), 28-46, 2012

[12] Magana, A. J., Marepalli, P. \& Clark, J. V., "Work in Progress Integrating Computational and Engineering Thinking through Online Design and Simulation of Multidisciplinary Systems", 41st ASEE/IEEE Frontiers in Education Conference, October 12-15, 2011.

[13] Kazimoglu, C., Kiernan, M., Bacon, L. \& MacKinnon, L., "Understanding Computational Thinking Before Programming: Developing Guidelines for the Design of Games to Learn Introductory Programming Through Game-Play", International Journal of Game-Based Learning, 1(3), 30-52, 2011.

[14] Shulman, L., "Those who understand: Growth in teaching", Educational Researcher, 15(2), 4-14, 1986.

[15] Simon, H. A., The sciences of the artificial, MIT-press, Cambridge/Mass., 1970

[16] Niss, M., "What does it mean to be a competent mathematics teacher? A general problem illustrated by examples from Denmark", Proceedings of the $23^{d}$ Conference on Mathematics Education, Hellenic Mathematical Society, pp. 39-47, Patras, Greece, 2006.

[17] Voskoglou, M. Gr., "The role of the teacher for the learning of mathematics" (Workshop), Proceedings CIEAEM 59, 278-283, Dobogoko, Hungary, 2007.

[18] Von Glaserseld, E., "Learning as a Constructive Activity", in C. Janvier (Ed), Problems of representation in the teaching and learning of mathematics, Lawrence Erlbaum, Hillsdale, N. J., 1987 .

[19] Jaworski, B., "Theory and practice in mathematics teaching development: Critical inquiry as a mode of learning in teaching", Journal of Mathematics Teacher Education, 9, 187-211, 2006.

[20] Elbers, E., "Learning and teaching mathematics in a community of inquiry", Educational Studies in Mathematics, 54, 77-99, 2003.

[21] Goos, M., "Learning Mathematics in a Classroom Community of Inquiry", Journal for Research in Mathematics Education, 35(4), 259-291, 2004.

[22] Lieberman, A., Miller, L., Teachers in Professional Communities Improving Teaching and Learning, Teachers College Press, New York, 2008.

[23] Bevan, B., "Developing communities of practice for middle school math teachers", 2011, retrieved from http://www.relatingresearchtopractice.org/article/63.

[24] Goos, M., "Communities of practice in mathematics teacher education", in S. Lerman (Ed.), Encyclopedia of Mathematics Education, pp. 82-84, Dordrecht, Netherlands: Springer, 2014.

C The Author(s) 2019. This article is an open access article distributed under the terms and conditions of the Creative Commons Attribution (CC BY) license (http://creativecommons.org/licenses/by/4.0/). 